\title{
Erratum to: Which pamidronate protocol is the best for treating osteoporosis in beta-thalassemia major?
}

\author{
Mehrnoush Kowsaryan $^{1} \cdot$ Shiva Rahimi $^{2} \cdot$ Mandana Zafari $^{3} \cdot$ Mehran Fazli $^{2}$. \\ Masoomeh Mousavi $^{1}$
}

Published online: 26 August 2016

(C) Springer-Verlag Berlin Heidelberg 2016

Erratum to: Annals of Hematology 95(3): 383-386

DOI: $10.1007 / \mathrm{s} 00277-015-2564-\mathrm{Z}$

Some authors of this article was missing in the original version. Complete list of author names and their affiliations are presented here.

The online version of the original article can be found at http://dx.doi.org/ 10.1007/s00277-015-2564-z.

Mehrnoush Kowsaryan

mekowsarian@gmail.com

1 Hemoglobinopathy Institute, Thalassemia Research Center, Mazandaran University of Medical Science, Sari, Iran

2 Mazandaran University of Medical Science, Sari, Iran

3 Department of Midwifery, Sari Branch, Islamic Azad University, Sari, Iran 